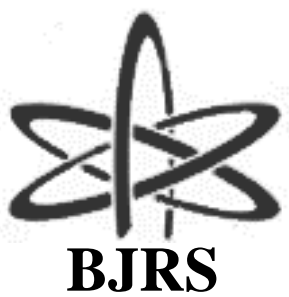

BRAZILIAN JOURNAL

OF

RADIATION SCIENCES

09-02A (2021) 01-14

\title{
Modification of fuel performance code to evaluate iron- based alloy behavior under LOCA scenario
}

\author{
C. Giovedi ${ }^{\mathrm{a}}$; A. Abe ; R. O. R. Muniz ; D. S. Gomes ${ }^{\mathrm{b}}$; A. T. Silva ${ }^{\mathrm{b}}$; M. R. Martins ${ }^{\mathrm{a}}$ \\ ${ }^{a}$ Analysis, Evaluation and Risk Management Laboratory (POLI / USP - SP), Av. Prof. Mello Moraes 2231, 05508- \\ 000, São Paulo, SP, Brazil \\ claudia.giovedi@labrisco.usp.br \\ ${ }^{b}$ Nuclear and Energy Research Institute (IPEN / CNEN - SP), Av. Professor Lineu Prestes 2242, 05508-000,
}

São Paulo, SP, Brazil

\begin{abstract}
Accident tolerant fuels (ATF) has been studied since the Fukushima Daiichi accident in the research efforts to develop new materials which under accident scenarios could maintain the fuel rod integrity for a longer period compared to the cladding and fuel system usually utilized in Pressurized Water Reactors (PWR). The efforts have been focused on new materials applied as cladding, then iron-base alloys appear as a possible candidate. The aim of this paper is to implement modifications in FRAPCON and FRAPTRAN fuel performance codes to evaluate the behavior of iron-based alloys under Loss-of-Coolant Accident (LOCA) scenario. For this, initially the properties related to the thermal and mechanical behavior of iron-based alloys were obtained from the literature, appropriately adapted and introduced in the fuel performance code subroutines. The adopted approach was step by step modifications, where different versions of the code were created. The assessment of the implemented modification was carried out simulating an experiment available in the open literature (IFA-650.5) related to zirconium-based alloy fuel rods submitted to LOCA conditions. The obtained results for the iron-based alloy were compared to those obtained using the regular version of the fuel performance code for zircaloy-4. The obtained results have shown that the most important properties to be changed are those from the subroutines related to the mechanical properties of the cladding. The results obtained have shown that the burst is observed at a longer time for fuel rods with iron-based alloy, indicating the potentiality of this material to be used as cladding with ATF purposes.
\end{abstract}

Keywords: accident tolerant fuel, fuel performance, iron-based alloy, LOCA. 


\section{INTRODUCTION}

The development of new materials to be applied in nuclear fuel rods requires an extensive research program comprising a series of experiments, computational simulation, and in-core tests. The activities involving all these steps spend at least 10 years. In this sense, the adaptation of recognized computational tools used to evaluate the fuel performance can help to save efforts and decrease the time to be consumed in the entire process.

Particularly, at this moment, the computational tools are important to perform a preliminary assessment of the behavior under irradiation of materials to be used in the framework of the Accident Tolerant Fuel (ATF) [1, 2] program. Considering that, the fuel performance codes available nowadays were developed in the $1970^{\prime}$ when the conventional $\mathrm{UO}_{2}-\mathrm{Zrloy}$ system was widely used. The utilization of these tools requires the previous adaptation with the introduction of properties of different materials in the source codes.

The ATF program arises after the Fukushima Daiichi accident [3] aiming to develop nuclear fuels with properties that can preserve the fuel rod integrity under normal operation and accident scenarios, for longer periods, compared to the conventional $\mathrm{UO}_{2}-\mathrm{Zrloy}$ system widely applied in nuclear power plants, all around the world.

The ATF program started in USA. Nowadays it involves efforts of different sectors from the international nuclear community. It includes universities, research institutes, regulatory authorities, and suppliers from all around the world. They aim to develop new materials to improve safety in nuclear power plants.

The major part of the studies being carried out in the framework of the ATF program is focused on the development and test of materials to be applied as cladding. These materials shall present good stability at high temperatures, especially in steam environment, to avoid the problem related to the hydrogen generation observed with zirconium-based alloys under accident scenarios. Also, the material shall present low neutron absorption cross-section, good mechanical stability under irradiation, and feasible manufacturing process. To comply with these requirements, the main materials under investigation are iron-based-alloys, and coated zirconium-based alloys. 
Iron-based alloys, specifically stainless steel 348 (AISI 348), present a higher thermal conductivity compared to zirconium-based alloys. Also, they present a thermal expansion coefficient approximately three times higher than that of zirconium-based alloys. Due to these properties, fuel rods manufactured using stainless steel as cladding under irradiation maintain the pellet-cladding gap open longer than those manufactured using zirconium-based alloys [4].

Concerning to mechanical properties, the creep deformation for zirconium-based alloys result from the combination of irradiation and thermal creep, which under steady state operation condition are of the same order of magnitude. For stainless steel rods under the same conditions only irradiation creep is significant. On the other hand, zirconium-based alloys creep rate can be about four times higher than AISI 348. AISI 348 presents a modulus of elasticity higher than zirconium-based alloys resulting that the cladding deformations will be significantly smaller during PCMI [4].

Iron-based alloys present an important advantage compared to zirconium-based alloys related to the reduction of the probability of the violent oxidation reaction at high temperatures. The good performance of iron-based alloys as cladding under steady-state and operational transients is wellknown from the previous experience of the first generation of PWR [5]. However, the performance of these materials under accident scenarios shall be better evaluated.

The aim of this paper is to discuss the results obtained with the modification, step by step, of the FRAPTRAN code to evaluate the behavior of stainless steel 348 as cladding material under LOCA scenario.

\section{MATERIALS AND METHODS}

\subsection{LOCA Test Case}

The data related to the test case used in this paper were obtained in the open literature [11] for the experiment IFA-650.5 performed in the framework of Halden Reactor Project to study the behavior of $\mathrm{UO}_{2} /$ Zircaloy-4 fuel rod under LOCA scenario.

The IFA-650.5 test fuel rod was re-fabricated from an irradiated PWR with a high average burnup of $83 \mathrm{MWd} / \mathrm{kgU}$. The base irradiation of the full-length rod comprised about 2000 effective full power days. The main characteristics of the IFA-650.5 fuel rod are summarized in Table 1 below. 
Table 1: IFA-650.5 fuel rod main characteristics.

\begin{tabular}{cc}
\hline Fuel type & PWR \\
\hline Fuel material & $\mathrm{UO}_{2}$ \\
\hline Fuel pellet diameter $(\mathrm{mm})$ & 9.132 \\
\hline Fuel pellet length $(\mathrm{mm})$ & 11 \\
\hline Fuel dish depth $(\mathrm{mm})$ & 0.28 \\
\hline Fuel dish width $(\mathrm{mm})$ & 1.2 \\
\hline Fuel density $(\% \mathrm{TD})$ & 94.8 \\
\hline Fuel enrichment $(\mathrm{w} / \mathrm{o} \%)$ & 3.5 \\
\hline Cladding material & $\mathrm{DX}$ ELS0.8b \\
\hline Cladding outer diameter $(\mathrm{mm})$ & 10.735 \\
\hline Cladding wall thickness $(\mathrm{mm})$ & 0.721 \\
\hline Fuel rod burnup $(\mathrm{MWd} / \mathrm{kgU})$ & 83 \\
\hline Fuel rod total length $(\mathrm{mm})$ & 4800 \\
\hline Fuel rod gap $(\mathrm{mm})$ & 0.0805 \\
\hline Fuel rod plenum volume $\left(\mathrm{cm}^{3}\right)$ & 15 \\
\hline Fuel rod fill gas & $90 \%$ Ar $+10 \% \mathrm{He}$ \\
\hline Fill pressure $(\mathrm{MPa})$ & 4.0 \\
\hline
\end{tabular}

\subsection{Fuel Performance Code Modification}

To evaluate the fuel performance under accident scenarios of a fuel rod manufactured using ironbased alloy as cladding, it is necessary to adapt conventional steady-state and transient codes implementing the properties of this material into the source codes.

The codes applied in this paper for steady-state and transients were, respectively, FRAPCON and FRAPTRAN [6]. The first step consisted in introduce the properties of stainless steel 348 in the FRAPCON source code. The results obtained for a test case using the original and the modified versions of the code under the same power history at steady-state scenario were previously reported [4].

Considering that, the FRAPTRAN code shares with FRAPCON some subroutines related to the cladding, part of the modifications already implemented in the modified version of FRAPCON code for AISI 348, can be used to change the FRAPTRAN code. Then, initially the following subroutines from FRAPCON code were used in the FRAPTRAN: CCP, CELMOD, CSHEAR, CMHARD, 
CTHEXP, CTHCON, ZOEMIS, and ZOTCON. The modification constitutes of first FRAPTRAN modified version obtained for AISI 348 in this assessment, identified as Modified Version 1.

After this, a second modified version was created considering the mechanical properties in the CMLIMT and CKMN subroutines, which calculate the limits of mechanical strain and the plastic strain for the cladding, respectively.

The modification was performed introducing in the code the data related to the burst stress as function of temperature for AISI 304 obtained from the literature [7], according to the equation 1:

$$
\text { ctstrt }=\left(599,98-0 \cdot 73269 \cdot \mathrm{Tc}+0,0002143 \cdot \mathrm{Tc}^{2}\right) \cdot 1 \cdot 0 \mathrm{~d}+06(\mathrm{~Pa})
$$

where:

ctstrt is the tangential component of real stress at burst; and

Tc is the temperature in ${ }^{\circ} \mathrm{C}$.

The stress-strain behavior in the FRAPTRAN code is described using two different correlations based on stress [8]. The deformation in the elastic region is described by the Hooke's law as shown in equation 2:

$$
\sigma=E \cdot \varepsilon
$$

where:

$\sigma$ is the stress;

$E$ is the modulus of elasticity; and

$\varepsilon$ is the strain.

The elastic strain is described by a power law as presented in equation 3 below.

$$
\sigma=K \cdot \varepsilon^{n} \cdot\left(\frac{s}{10^{-s}}\right)^{m}
$$

where:

$K$ is the strength coefficient;

$n$ is the strain hardening exponent;

$m$ is the strain rate sensitivity constant; and

$\dot{\varepsilon}$ is the strain rate.

From equations 2 and 3 was obtained the stress-strain curve with yield strength $(Y S)$, ultimate tensile strength (UTS), and uniform elongation (UE) for the studied material. 
The coefficient $K$ and the exponent $n$ in equation 3 as function of temperature for stainless steel were obtained from reference [9]. The value for the constant $m$ was not obtained for stainless steel. Then, in the code modification process, the $m$ value was kept the same of the zircaloy, considering that the literature shows that $\mathrm{m}$ values for metals are about 0.1 to 0.2 [10].

The second modified version including the properties of stainless steel in the subroutines CMLIMT and CKMN is identified in this paper as Modified Version 2.

\section{RESULTS AND DISCUSSION}

Due to the fact that this paper is focused in the modification of the FRAPTRAN code to evaluate the behavior of AISI 348 under LOCA scenario, the results presented below show only the performance of the fuel rod during the accident. Then, at time 0 starts the LOCA followed by the blowdown phase and the progression of the accident until $1200 \mathrm{~s}$.

Figures 1 to 4 present the comparison of some results obtained using the original version of the FRATRAN code for zircaloy and those obtained from the Modified Version 1 for AISI 348, which considers the original mechanical properties of zircaloy, using IFA-650.5 as LOCA test case.

Figure 1: Internal pressure evolution as function of time for IFA-650.5 using original FRAPCON/FRAPTRAN codes for zircaloy and the Modified Version 1 for AISI 348

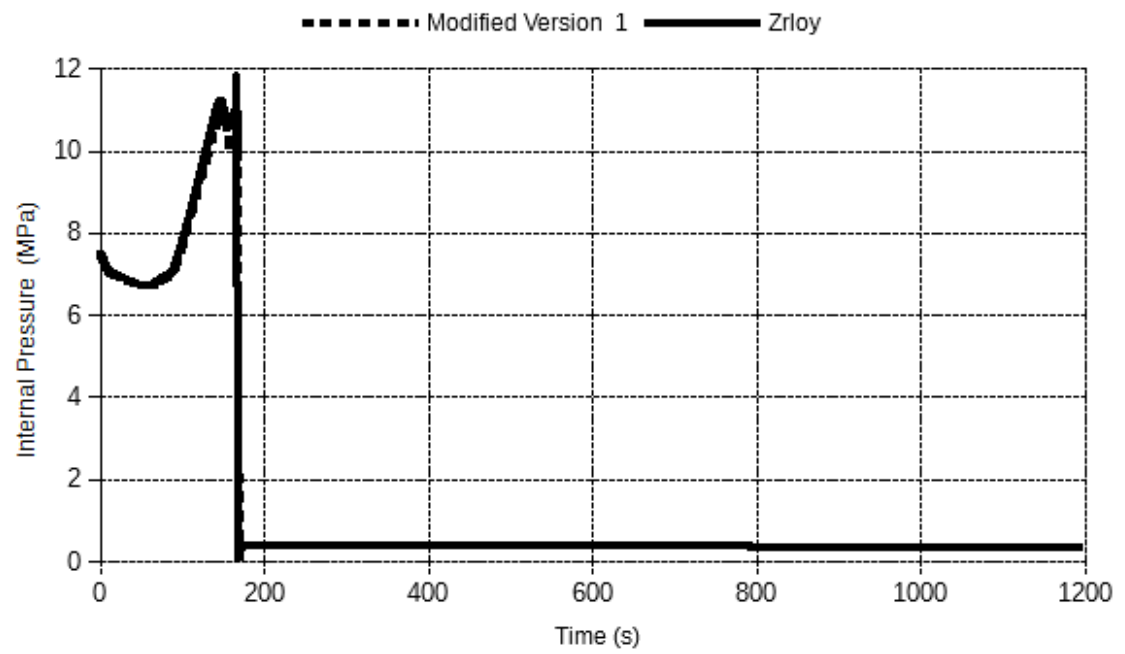


Figure 2: Cladding hoop stress evolution as function of time for IFA-650.5 using original FRAPCON/FRAPTRAN codes for zircaloy and the Modified Version 1 for AISI 348

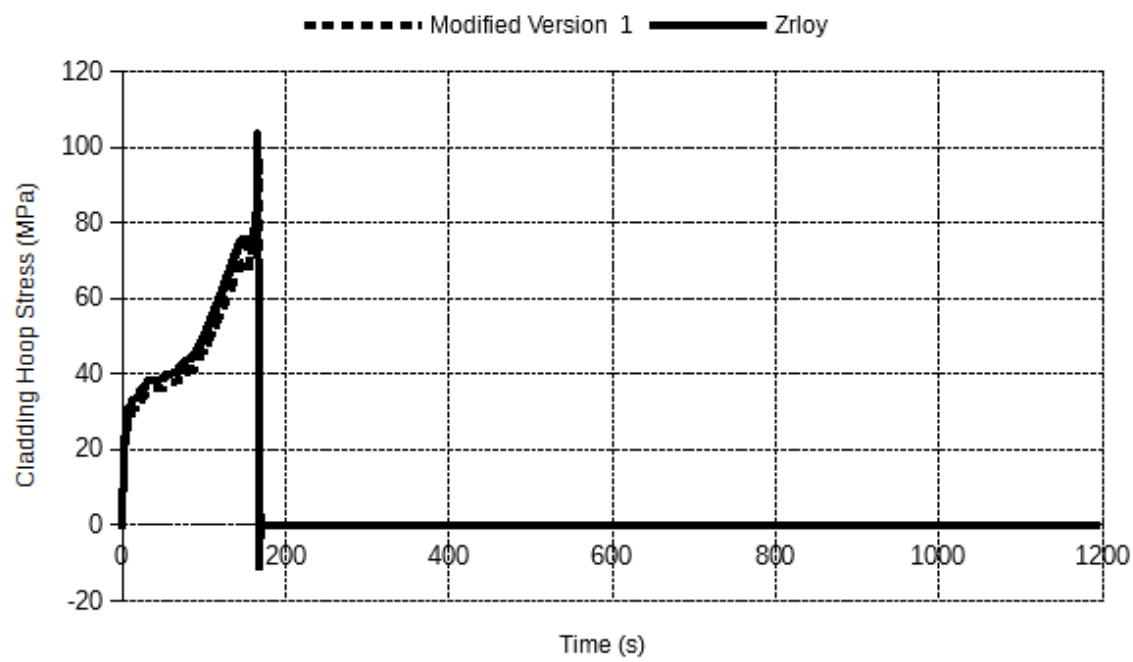

Figures 1 and 2 show that the internal pressure and the cladding hoop stress are slightly lower for the AISI 348 when compared to the zircaloy until the cladding burst due to the difference of thermal properties. However, the burst occurs at the same time for both materials because the driving force is associated to the mechanical properties of the cladding materials, which are the same in both versions of the codes.

Figure 3: Structural radial gap evolution as function of time for IFA-650.5 using original FRAPCON/FRAPTRAN codes for zircaloy and the Modified Version 1 for AISI 348

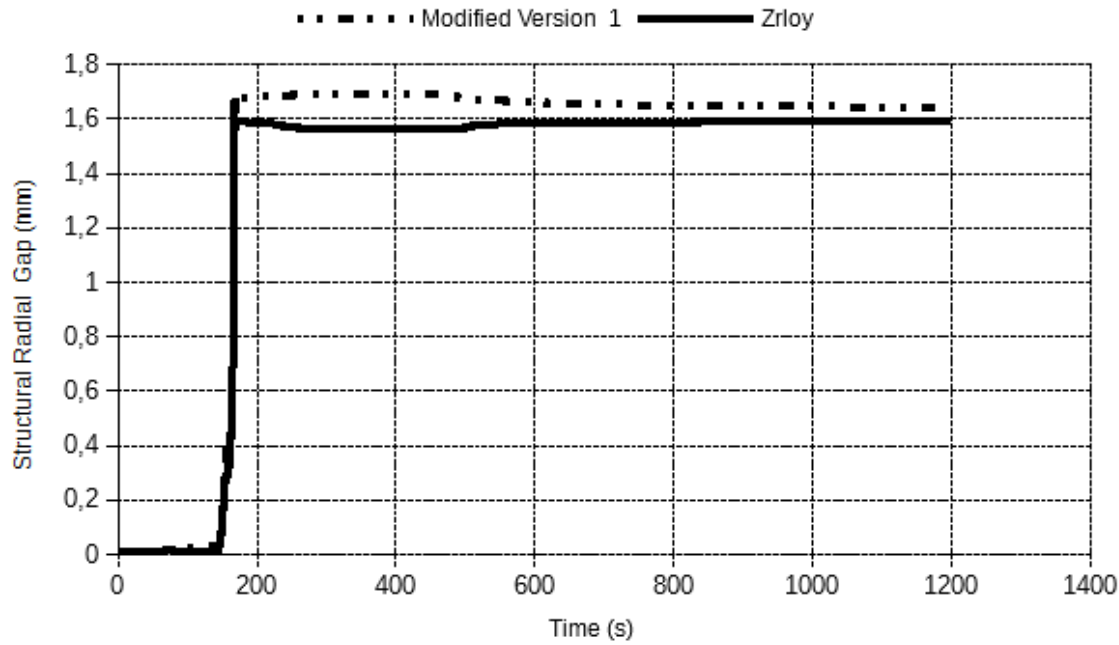


Figure 4: Fuel centerline temperature evolution as function of time for IFA-650.5 using original FRAPCON/FRAPTRAN codes for zircaloy and the Modified Version 1 for AISI 348

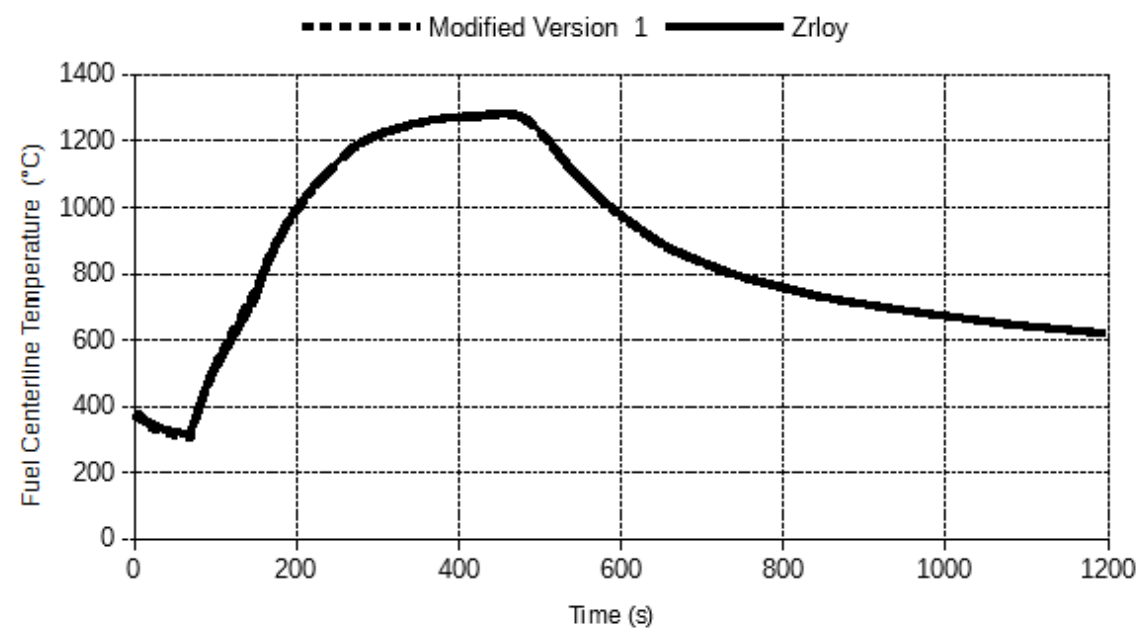

Despite of the larger gap observed for AISI 348 compared to zircaloy under steady state irradiation [4], this phenomenon is not observed during the LOCA due to the short time scale of the accident. Because of this, no difference is observed in the fuel centerline temperature for both materials, as shown in Figure 4.

The results obtained using the Modified Version 1 of the FRAPTRAN code show that some thermal and mechanical properties are not ruling the main changes in the fuel behavior under LOCA scenario. Even considering that AISI 348 and zircaloy present different thermal properties, the effect in the global performance is not significant and observed in the time scale of the accident.

A new round of simulations was carried out using the Modified Version 2 of FRAPTRAN code, which includes modifications in the subroutines related to the mechanical properties of the cladding material. Some results comparing the behavior of zircaloy using the original code version and AISI 348 with the Modified Version 2 are presented in Figures 5 to 8. 
Figure 5: Internal pressure evolution as function of time for IFA-650.5 using original FRAPCON/FRAPTRAN codes for zircaloy and the Modified Version 2 for AISI 348

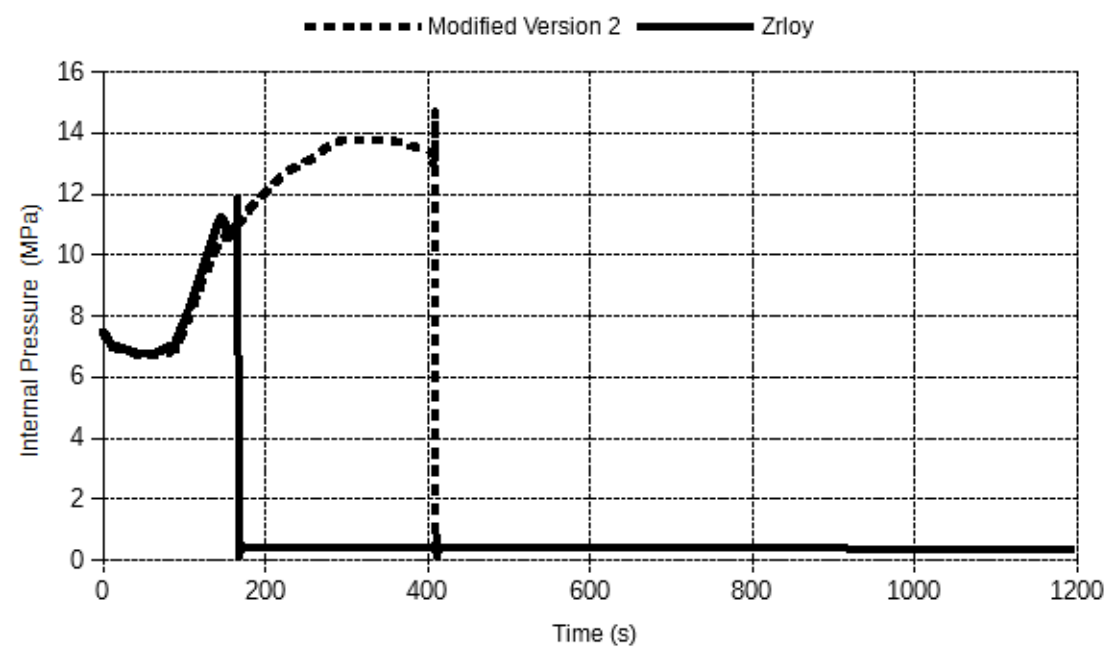

Figure 6: Cladding hoop stress evolution as function of time for IFA-650.5 using original FRAPCON/FRAPTRAN codes for zircaloy and the Modified Version 2 for AISI 348

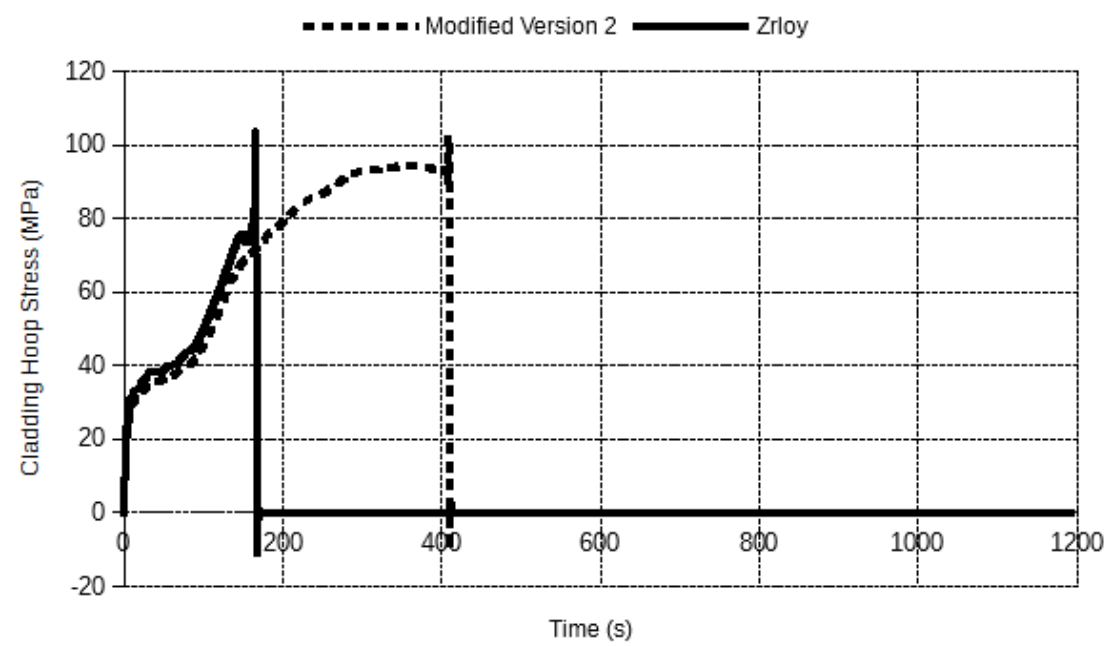

Figure 5 shows that the modifications implemented in the code related to the mechanical properties of AISI 348 (Modified Version 2) produce changes in the behavior under LOCA scenario for the AISI 348 fuel rod and it experiences the burst about $220 \mathrm{~s}$ after the zircaloy. The internal pressure and the hoop stress for AISI 348 increase as function of time and reach higher values compared to 
zircaloy prior to the burst due to the higher mechanical limits of AISI 348. These data agree with the literature data related to the burst behavior of different iron-based alloys at high temperature [7]. The gap evolution presented in Figure 7 shows the different behavior of AISI 348 and zircaloy fuel rods during LOCA. Before the zircaloy fuel rod burst, the gap for both materials is similar due to the short time scale of the accident. After the zircaloy burst, the gap of the AISI 348 fuel rod increases due to the cladding deformation until to experience the burst.

Figure 7: Structural radial gap evolution as function of time for IFA-650.5 using original FRAPCON/FRAPTRAN codes for zircaloy and the Modified Version 2 for AISI 348

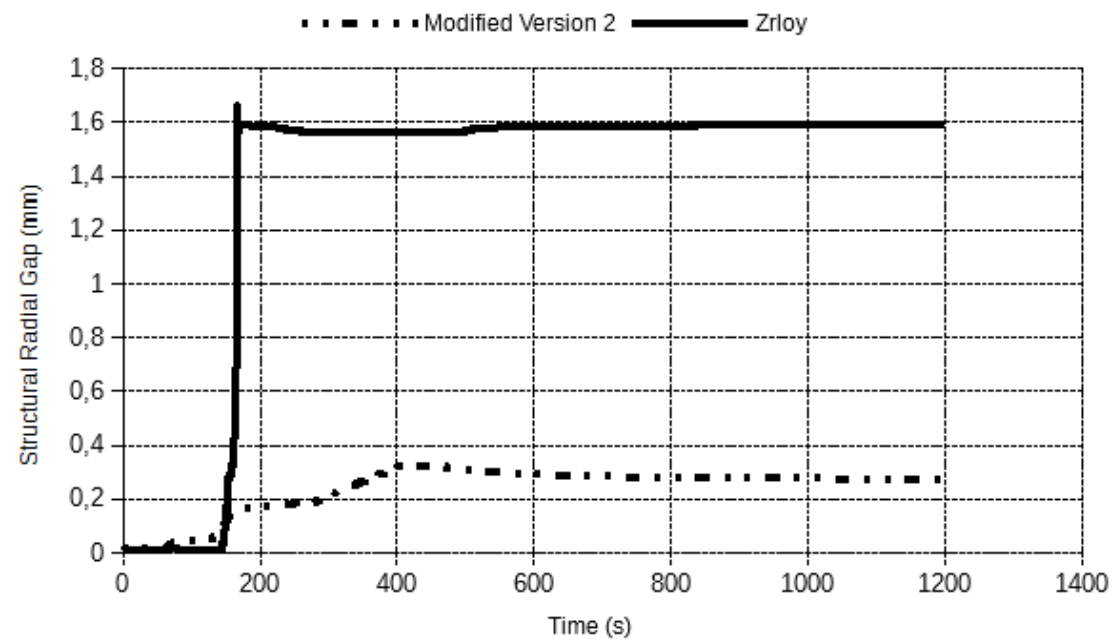

Figure 8: Fuel centerline temperature evolution as function of time for IFA-650.5 using original FRAPCON/FRAPTRAN codes for zircaloy and the Modified Version 2 for AISI 348

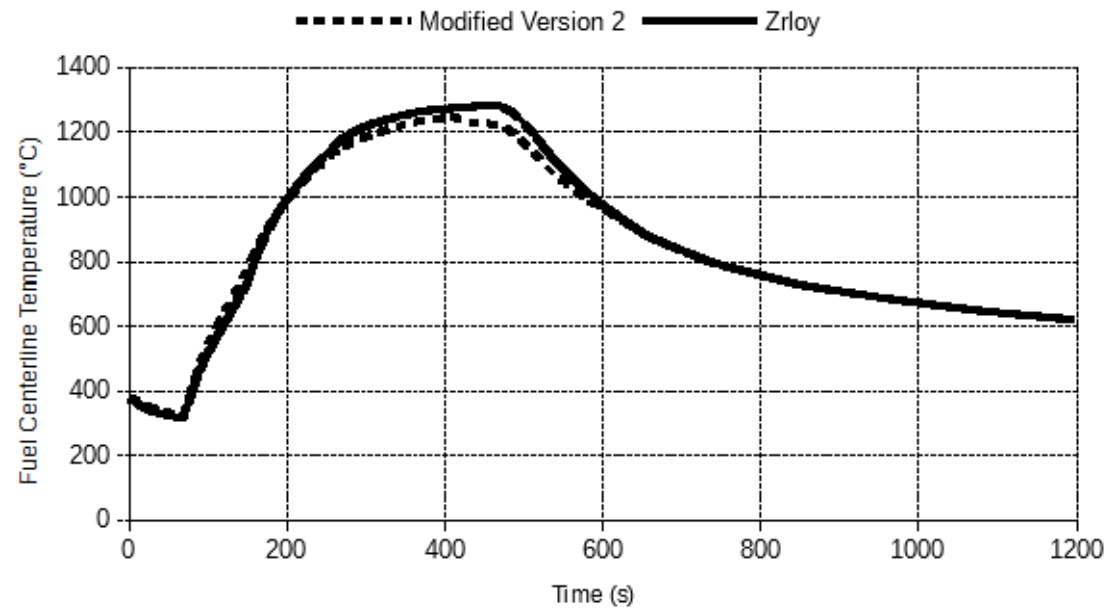


Figure 8 shows that the fuel centerline temperatures for both materials are remarkably similar during all the studied time scale and the AISI 348 fuel rod experiences the burst when the highest temperature is observed. Then, the temperature plays an important role in the burst phenomena for AISI 348.

The comparison of the results obtained using two different modified versions of FRAPTRAN code for AISI 348, the first one without considering mechanical properties of the cladding material and the second one introducing these data, shows that the mechanical properties related to elastic and plastic deformation of the cladding play an important role in the fuel behavior under LOCA scenario. Consequently, these properties shall be considered to obtain fuel performance codes that are able to reproduce the expected behavior for different cladding materials under accident scenarios.

\section{CONCLUSION}

The recent efforts to develop ATF have shown that iron-based alloys are potential candidates to be studied to replace the zirconium-based alloys currently used as cladding. In this sense, the evaluation of the behavior of these materials under irradiation, and specifically under accident scenarios, were studied. The modification of conventional fuel performance codes to assess the fuel performance of different claddings and fuels materials represent an important tool in the ATF development process [12-14].

The preliminary results obtained from the modification of FRAPTRAN code step by step to evaluate the fuel performance of a fuel rod manufactured using stainless steel during LOCA show that the most important properties are those related to the mechanical behavior of the cladding under accident conditions, mainly the plastic strain which will be determinant to define the occurrence of burst. The results also have shown that AISI 348 experiences the burst at a longer time compared to zircaloy, and this is one of the requirements that a material shall present to be used as cladding with ATF purposes. Moreover, AISI 348 presents improved reaction kinetics with steam at high temperatures.

\section{ACKNOWLEDGMENT}


The authors are grateful for the support received from Nuclear Energy Research Institute (Instituto de Pesquisas Energéticas e Nucleares; IPEN), associated with the National Nuclear Energy Commission (Comissão Nacional de Energia Nuclear; CNEN), and University of São Paulo.

\section{REFERENCES}

1. BRAGG-SITTON, S. Development of advanced accident tolerant fuels for commercial LWRs. Nuclear News, p. 83-91, 2014.

2. GOLDNER, F. Development strategy for advanced LWR fuels with enhanced accident tolerance. USA. 2012. Available at: <http:// energy.gov/sites/prod/files/061212 Goldner - NEAC Presentation (FINAL).pdf>. Last accessed: 24 Nov. 2017.

3. AKIYAMA, N.; SATO, H.; NAITO, K.; NAOI, Y.; KATSUTA, T. The Fukushima nuclear accident and crisis management - Lessons for Japan-U.S. Alliance Cooperation. Sasakawa Peace Foundation, Tokyo, 2012.

4. ABE, A.; GIOVEDI, C.; GOMES, D. S.; TEIXEIRA E SILVA, A. Revisiting stainless steel as PWR fuel rod cladding after Fukushima Daiichi accident. EPJ Nuclear Sci. Technol., v. 8, p. 973-980, 2014.

5. S. M. Stoller Corporation. An evaluation of stainless steel cladding for use in current design LWRs. NP-2642, EPRI, 1982. 251p.

6. GEELHOOD, K. J.; LUSCHER, W. G.; BEYER, C. E.; FLANAGAN, M. E.; FRAPCON-3.4: A computer code for the calculation of steady-state thermal-mechanical behavior of oxide fuel rods for high burnup. U.S.NRC, NUREG/CR-7022, Washington, 2011.

7. MASSEY, C. P.; TERRANI, K. A.; DRYEPONDT, S. N.; PINT, B. A. Cladding burst behavior of Fe-based alloys under LOCA. Journal of Nuclear Materials, v. 470, p. 128-138, 2016.

8. PNNL - Pacific Northwest National Laboratory. Stress/strain correlation for zircaloy, PNNL17700, Battelle: PNNL, 2008. 42p.

9. DESU, R. K.; KRISHNAMURTHY, H. N.; BALU, A.; GUPTA, A. K.; SiNGH, S. K. Mechanical properties of austenitic stainless steel $304 \mathrm{~L}$ and $316 \mathrm{~L}$ at elevated temperatures. J. Mater. Res. Technol., v. 5, p. 13-20, 2016.

10. GARCIA, A.; SPIM, J. A.; SANTOS, C. A. Ensaios dos materiais, $2^{\text {th }}$ ed., Rio de Janeiro: 
LTC, 2012.

11. MANNGARD, T.; STENGARD, J. Evaluation of the Halden IFA-650 loss-of-coolant accident experiments 5, 6 and 7. Swedish Radiation Safety Authority, Sweden, 2014. 46p.

12. ABE, A.; SILVA, A. T.; GIOVEDI, C.; MELO, C.; GOMES, D. S.; MUNIZ, R. R. Development and application of modified fuel performance code based on stainless steel as cladding under steady state, transient and accident conditions. Fuel Modelling in Accident Conditions (FUMAC) Final Report of a Coordinated Research Project, IAEA-TECDOC-1889, 2019.

13. GIOVEDI, C.; MARTINS, M. R.; ABE, A.; REIS, R.; SILVA, A. T. Reactivity Initiated Accident Assessment for ATF Cladding Materials, Technical Meeting on Modelling of Fuel Behaviour in Design Basis Accidents and Design Extension Conditions, Shenzhen, China, 2019.

14. GIOVEDI, C.; MARTINS, M. R.; ABE, A.; MUNIZ, R. R.; GOMES, D. S.; Silva, A. T. Fuel performance assessment of enhanced accident tolerant fuel using iron-based alloys as cladding, TopFuel 2018, Czech Republic, 2018. 